\title{
The Method of Evaluation on Mathematical Teacher's Ability in the Training Mode of Innovative Talents
}

\author{
Zhong YiHua \\ Dept. of Sciences, Southwest Petroleum University \\ SWPU \\ Chengdu, China \\ zhongyh_65@126.com
}

\author{
Lin $\mathrm{XuXu}$ \\ Dept. of Sciences, Southwest Petroleum University \\ SWPU \\ Chengdu, China
}

\author{
Liu YuXin \\ Dept. of Sciences, Southwest Petroleum University \\ SWPU \\ Chengdu, China
}

\begin{abstract}
Teacher's ability is the most important and most direct factor influencing the quality of talents training. Talents determine the implementation of the "Chinese Dream". With the existing situation of teacher's ability not meeting the requirement for training innovative talents, the evaluation index system of mathematical teacher's ability was first formulated based on the demand for mathematics ability in the training mode of innovative talents. Then, an improved method and model of evaluating mathematical teacher's ability were proposed by using the method and theory on combination weighting, an improved comprehensive cloud and similar cloud theory. Finally, a case study shows that the method and model presented in the paper are correct, which may give helpful proposal for improving teacher's ability.
\end{abstract}

Keywords-combination weighting; improved comprehensive cloud; similar cloud theory; teaching ability;

\section{INTRODUCTION}

The 21st century is the Age when human beings depend on knowledge innovation. Because technology and talent are increasingly becoming the decisive factors of national prosperity and progress, almost each country in the world takes national innovative talents resources as the core element of a strategic resource and technology competitiveness improvement. Esp., our country also put forward the strategy of constructing innovative countries, and emphasized the training of creative talents in recent years. Therefore, the cultivation of innovative talents becomes the hot topic of education and the focal point of research.

In order to meet the needs of times and social development, the cultivation of innovative talents requests higher level and stronger ability teachers who have the idea of modern education, innovative consciousness and teacher's ability include basic ability, teaching ability, scientific research ability etc. As an example, mathematical innovative talents should possess solid mathematical knowledge, strong mathematical divergent thinking and extrapolate, fusion penetration ability, the ability of applying knowledge they have learned in the study and life practice to analyze and solve problems and thinking way of reforming related aspects of the innovation. However, mathematical teacher's ability in ordinary engineering colleges and universities can't completely meet the requirement for training innovative talents. Thus, it is very important to improve teachers' ability for these higher schools, which key problem is to study how to evaluate mathematical teacher's ability.

So far, many experts and scholars have done a lot of research work on the teaching. They mainly focused on the evaluation of teaching performance and teacher's teaching competence, the study of teacher quality and teacher development. The methods used commonly include analytic hierarchy process (AHP) ${ }^{[1]}$, fuzzy comprehensive evaluation method ${ }^{[2]}$, and grey correlation analysis ${ }^{3]}$ etc. In these studies, they seldom consider the following problems: (1) The evaluation for mathematical teacher's ability in the training mode of innovative talent is very few studied, and the evaluation index system of teacher's ability is still not formed relatively perfect and ready-made. (2) Whether it is reasonable or not to weight the weight of evaluation indexes only using a single weighting method of subjectively or objectively weighting methods. (3) The existing evaluation methods do not consider the uncertainty under the process of evaluation, especially the fuzziness and randomness.

With above three problems, we devote ourselves to study the method of evaluation on mathematical teacher's ability in modern education mode. It mainly includes establishing evaluation index system of mathematical teacher's ability through investigating and analyzing relative references, studying the method about combination weighting by combining Delphi 
$\operatorname{method}^{[4]}$ with Entropy value method ${ }^{[5]}$, proposing a new evaluating method with the fuzziness and randomness among various factors in teacher's ability using cloud model ${ }^{[6]}$ which is the transformation between qualitative and quantitative model presented by De-yi li and the theories of comprehensive cloud and similar cloud.

\section{THE EVALUATION INDEX SYSTEM OF MATHEMATICAL TEACHER'S ABILITY}

Since many factors may influence the competence of a teacher, the structure of the evaluation index system of teacher's ability plays an important role ${ }^{[7]}$. Thus, we first summarized systematically the basic characteristics, quality characteristics and structural characteristics of innovative talents. Then we studied the requirements of ability that a mathematical teacher would posses for training innovative talents. Finally, we formulated the evaluation index system of teacher's ability by investigating and analyzing the existing references about the composition of teacher's ability and combining with above requirements of teacher's ability. Therefore, mathematical teacher's ability can be divided into general ability including basic ability, teaching ability, scientific research ability and other abilities such as cooperate, innovation ability and the ability of lifelong learning in the innovative talent training mode. Where other abilities are key factors of the teacher's ability in the mode of cultivating creative talents, which is distinguish from mathematical teacher's ability in other types of talent training mode. The evaluation index system of mathematical teacher's ability is as Tab. I.

\section{THE METHOD AND MODEL OF EVALUATING MATHEMATICAL TEACHER'S ABILITY}

\section{A. The method of combination weighting}

For subjective weighting and objective weighting have themselves advantages and disadvantages, we proposes a new weighting method of determining combination weight, which combines Delphi method with Entropy weight method to improve the accuracy of index weight in the multi-index comprehensive evaluation.

The principle of combination weighting is as follows: denote the weight of each index by using separately Entropy weight method and expert judgment method (Delphi method) as $\omega_{j}^{(\mathrm{e})}=\left(\omega_{1}^{(e)}, \omega_{2}^{(\mathrm{e})}, \cdots, \omega_{n}^{(\mathrm{e})}\right)$ and $\omega_{j}^{(\mathrm{a})}=\left(\omega_{1}^{(\mathrm{a})}, \omega_{2}^{(\mathrm{a})}, \cdots, \omega_{n}^{(\mathrm{a})}\right)$, then according to the comprehensive weights theory ${ }^{[8]}$, we present a method to compute combination weight which may be calculated by (1).

$$
\omega_{j}=\frac{\omega_{j}^{(\mathrm{a})} \cdot \omega_{j}^{(\mathrm{e})}}{\sum_{j=1}^{n}\left(\omega_{j}^{(\mathrm{a})} \cdot \omega_{j}^{(\mathrm{e})}\right)} j=1,2, \cdots, n
$$

\section{B. The evaluation model of teacher's ability based on} comprehensive cloud

Aiming at the fuzzy and random uncertainty in teacher's ability evaluation as well as difficulty to represent accurately them by existing model of evaluation, we study its new evaluation model by using cloud theory ${ }^{[9]}$.

1) Cloud theory

Suppose $U$ is a quantitative domain expressed by precise values, and $C$ is a qualitative concept on the domain $U$. If the quantitative value $x \in U$, and $x$ is a random realization to the qualitative concept $C$, whose membership $\mu(x) \in[0,1]$ for $C$ is a random number with stable tendency:

$$
\mu: U \rightarrow[0,1], \forall x \in U, x \rightarrow \mu(x)
$$

Then, the distribution of $x$ on the domain $U$ is called as cloud, and each $x_{i}$ is called as droplet. The more cloud droplets, the more overall characteristics of the qualitative concept can be reflected.

\begin{tabular}{|c|c|c|}
\hline $\begin{array}{l}\text { Target } \\
\text { layer }\end{array}$ & $\begin{array}{l}\text { Primary } \\
\text { index }\end{array}$ & Secondary index \\
\hline \multirow{20}{*}{$\begin{array}{l}\text { Teacher's } \\
\text { ability }\end{array}$} & \multirow{6}{*}{$\begin{array}{c}\text { Basic } \\
\text { ability }\end{array}$} & General cognitive ability \\
\hline & & Educating ability \\
\hline & & Interpersonal skills \\
\hline & & Language competence \\
\hline & & Operate Ability \\
\hline & & Mathematics Professional ability \\
\hline & \multirow{5}{*}{$\begin{array}{l}\text { teaching } \\
\text { ability }\end{array}$} & $\begin{array}{l}\text { The ability to control subject } \\
\text { content }\end{array}$ \\
\hline & & $\begin{array}{c}\text { Teaching organization and } \\
\text { management ability }\end{array}$ \\
\hline & & The teaching monitoring capability \\
\hline & & Teaching reflection ability \\
\hline & & $\begin{array}{l}\text { The modern education technology } \\
\text { ability }\end{array}$ \\
\hline & \multirow{6}{*}{$\begin{array}{l}\text { Scientific } \\
\text { research } \\
\text { ability }\end{array}$} & Publishing paper ability \\
\hline & & Published monograph ability \\
\hline & & Writing teaching material ability \\
\hline & & Inventing patent ability \\
\hline & & Researching project ability \\
\hline & & Awarding achievement ability \\
\hline & \multirow{3}{*}{$\begin{array}{l}\text { Other abili- } \\
\text { ties }\end{array}$} & The ability to cooperate \\
\hline & & Innovation ability \\
\hline & & The ability of lifelong learning \\
\hline
\end{tabular}

\section{TABLE I. EVALUATION INDEX SYSTEM}

The overall characteristics of the uncertainty on concept can be expressed as cloud $C\left(E_{x}, E_{n}, H_{e}\right)$ with its three number features, i.e. expected value ( $\left.E_{x}\right)$, Entropy $\left(E_{n}\right)$, Super entropy $\left(H_{e}\right)$.

Combining positive cloud generator with inverse cloud generator, cloud generator can realize the qualitative and quantitative transformation at any time.

The comprehensive cloud technology is the concept generalization of cloud theory. Comprehensive cloud abstracts two or more clouds to one high level cloud, which means two or more same type linguistic values to be abstracted into a higher level concept language.

2) Cloud model of teacher's ability evaluation grades

According to the expert's knowledge and experience, teacher's ability can be divided into five grades: \{excellent, good, medium, pass, fail $\}$, Then, the number features of five grades are obtained according to relation table between number features of cloud model and domain ${ }^{[9]}$, as Tab. II. 
3) An improved comprehensive cloud model

Because the evaluation index system of teacher's ability has two levels of indicators in Tab. I, we adopt the method of comprehensive cloud theory to calculate the cloud model of upper indexes according to the cloud model of secondary indexes. Assume one of the primary indexes has $k$ secondary level indexes, cloud models of secondary level indexes and their corresponding weights are as follows:

$$
C\left(E_{x i}, E_{n i}, H_{e i}\right) \quad i=1,2, \cdots, k \quad \omega=\left\{\omega_{1}, \omega_{2}, \cdots, \omega_{k}\right\}
$$

Considering the connotation of entropy, we present a new comprehensive cloud computing formula based on the original cloud theory ${ }^{[10]}$ as (2).

TABLE II. RELATION BETWEEN NUMBER FEATURES OF CLOUD MODEL AND DOMAINS

$$
\begin{aligned}
& \begin{array}{|c|c|c|c|}
\hline \begin{array}{c}
\text { Domain } \\
\text { partition }
\end{array} & D_{1} \in\left[a_{1}, b_{1}\right] & D_{i} \in\left[a_{i}, b_{i}\right] & D_{5} \in\left[a_{5}, b_{5}\right] \\
\hline E_{x} & a_{1} & \left(a_{i}+b_{i}\right) / 2 & b_{5} \\
\hline E_{n} & \left(b_{1}-a_{1}\right) / 3 & \left(b_{i}-a_{i}\right) / 6 & \left(b_{5}-a_{5}\right) / 3 \\
\hline H_{e} & 0.05 & 0.05 & 0.05 \\
\hline
\end{array} \\
& E_{x}=\frac{\frac{E_{x 1} \times \omega_{1}}{E_{n 1}}+\frac{E_{x 2} \times \omega_{2}}{E_{n 2}}+\cdots+\frac{E_{x k} \times \omega_{k}}{E_{n k}}}{\frac{\omega_{1}}{E_{n 1}}+\frac{\omega_{2}}{E_{n 2}}+\cdots+\frac{\omega_{k}}{E_{n k}}} \\
& E_{n}=E_{n 1} \times \omega_{1}+E_{n 2} \times \omega_{2}+\cdots+E_{n k} \times \omega_{k} \\
& H_{e}=\frac{\frac{H_{e 1} \times \omega_{1}}{E_{n 1}}+\frac{H_{e 2} \times \omega_{2}}{E_{n 2}}+\cdots+\frac{H_{e k} \times \omega_{k}}{E_{n k}}}{\frac{\omega_{1}}{E_{n 1}}+\frac{\omega_{2}}{E_{n 2}}+\cdots+\frac{\omega_{k}}{E_{n k}}}
\end{aligned}
$$

By (2), the cloud model of other primary indexes and target layer can also be calculated.

\section{The measurement method of similar cloud}

If two or more clouds described in the same qualitative concept have a certain similarity, then these clouds are called as similar or equivalent cloud. Due to the particularity of the cloud itself, the similarity among the clouds can be measured by the distance of a large number of cloud droplets produced by cloud. Its method is as follows:

Step1 Through positive generator and the numerical features of target layer, ith cloud drop $x_{i}$ and its corresponding certain degree $y_{i}, i=1,2, \cdots, n$ can be got, where $y=\left[y_{1}, y_{2}, \cdots, y_{n}\right]$.

Step2 Ith cloud droplet $x_{i}, i=1,2, \cdots, n$ produced by Step 1 is taken as input of five cloud models on evaluation grades separately, calculating the certain degree that ith cloud droplet relates to qth evaluation grade of teacher's ability, denoted as $y_{q i}, q=1,2, \cdots, 5, i=1,2, \cdots, n$. Then the corresponding matrix of certain degree is shown as $Y$.

$$
Y=\left(y_{q i}\right)_{5 \times n}=\left[\begin{array}{lllll}
y_{11} & y_{12} & y_{13} & \cdots & y_{1 n} \\
y_{21} & y_{22} & y_{23} & \cdots & y_{2 n} \\
y_{31} & y_{32} & y_{33} & \cdots & y_{3 n} \\
y_{41} & y_{42} & y_{43} & \cdots & y_{4 n} \\
y_{51} & y_{52} & y_{53} & \cdots & y_{5 n}
\end{array}\right]
$$

Step3 Sorting the certain degree $y$ and $y_{q}=\left[y_{q 1}, y_{q 2}, \cdots y_{q n}\right]$ according to ascending order respectively to get $y^{\prime}=\left[y_{1}^{\prime}, y_{2}^{\prime}, \cdots, y_{n}^{\prime}\right]$ and $y_{q}{ }^{\prime}=\left[y_{q 1}{ }^{\prime}, y_{q 2}{ }^{\prime}, \cdots, y_{q n}{ }^{\prime}\right]$, calculating the distance $d_{q}$ between $y^{\prime}$ and $y_{q}^{\prime}$.According to the minimum principle, the distance $d_{l}=\min \left\{d_{1}, d_{2}, \cdots, d_{5}\right\}$ of the corresponding evaluation level is the final level of teacher's ability.

\section{APPLICATION STUDIES}

\section{A. The determinating of evaluation matrix}

In order to evaluate the ability level of a young mathematic teacher in our university in innovative talent training mode, we collected the information about 100 university mathematical teachers of different levels, including professor, associate professor, lecturer, teaching assistant, and scored respectively all the secondary indexes by hundred-mark system. Then, evaluating matrix is denoted as:

$$
A=\left[\begin{array}{cccc}
x_{11} & x_{12} & \cdots & x_{121} \\
x_{21} & x_{22} & \cdots & x_{221} \\
\cdots & \cdots & \cdots & \cdots \\
x_{1001} & x_{1002} & \cdots & x_{10021}
\end{array}\right]
$$

\section{B. The determinating of cloud model on evaluation grades}

According to Tab. II, the cloud model of evaluation grades is as Tab.III.

\section{The constructing of cloud model on target layer}

Using combination weighting method presented in section III, the weight of each index is given in Tab. IV. When the cloud model of each secondary index was got by positive cloud generator, and the cloud model of primary indexes was calculated by improved comprehensive cloud model by (2). Finally, the cloud model of target layer is also obtained as $C(89.452,2.372,0.05)$.

\section{The determinating the level of teacher's ability}

In order to determine the level of teacher's ability, the figures for similar cloud results are as Fig.l.

Fig. 1 shows that the 'good' rating curve is better matched with its evaluating result curve. From Fig.1.6, it can be seen very intuitively that most of the cloud droplets distribute in the region $[80,100]$. In order to ensure that the results are more accuracy, we calculated the distance of the cloud droplets' certainty between the target layer and evaluation grades by using the measurement method presented in III, as Tab. V. 
According to Fig. 1 and Tab. V, the teacher's ability is 'good'.

TABLE III. CLOUD MODEL OF EVALUATION GRADES

\begin{tabular}{|c|c|c|}
\hline $\begin{array}{c}\text { Evaluation } \\
\text { grades }\end{array}$ & Domain partition & Number feature \\
\hline fail & {$[0,60]$} & $(0,20,0.05)$ \\
\hline pass & {$[60,70]$} & $(65,10 / 6,0.05)$ \\
\hline medium & {$[70,80]$} & $(75,10 / 6,0.05)$ \\
\hline good & {$[80,90]$} & $(85,10 / 6,0.05)$ \\
\hline excellent & {$[90,100]$} & $(100,10 / 3,0.05)$ \\
\hline
\end{tabular}
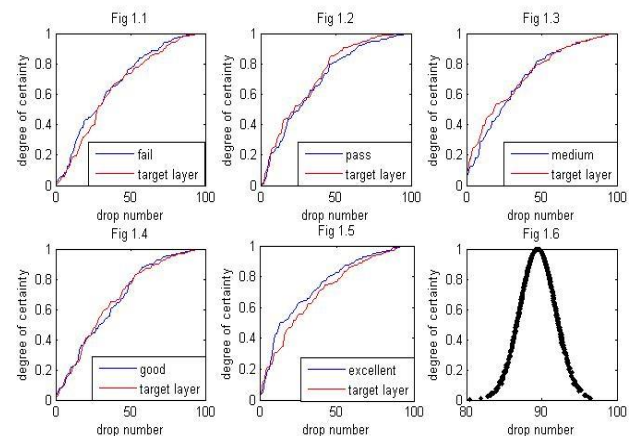

Fig. 1. similar cloud results

TABLE IV. THE WEIGHT OF EACH INDEX

\begin{tabular}{|c|c|c|c|}
\hline Primary index & weight & Secondary index & weight \\
\hline \multirow{6}{*}{$U_{1}$} & \multirow{6}{*}{0.156} & $U_{11}$ & 0.207 \\
\hline & & $U_{12}$ & 0.222 \\
\hline & & $U_{13}$ & 0.034 \\
\hline & & $U_{14}$ & 0.035 \\
\hline & & $U_{15}$ & 0.069 \\
\hline & & $U_{16}$ & 0.433 \\
\hline \multirow{5}{*}{$U_{2}$} & \multirow{5}{*}{0.305} & $U_{21}$ & 0.598 \\
\hline & & $U_{22}$ & 0.108 \\
\hline & & $U_{23}$ & 0.068 \\
\hline & & $U_{24}$ & 0.043 \\
\hline & & $U_{25}$ & 0.183 \\
\hline \multirow{6}{*}{$U_{3}$} & \multirow{6}{*}{0.397} & $U_{31}$ & 0.205 \\
\hline & & $U_{32}$ & 0.146 \\
\hline & & $U_{33}$ & 0.155 \\
\hline & & $U_{34}$ & 0.143 \\
\hline & & $U_{35}$ & 0.208 \\
\hline & & $U_{36}$ & 0.143 \\
\hline \multirow{3}{*}{$U_{4}$} & \multirow{3}{*}{0.142} & $U_{41}$ & 0.242 \\
\hline & & $U_{42}$ & 0.702 \\
\hline & & $U_{43}$ & 0.056 \\
\hline
\end{tabular}

TABLE V. THE DISTANCE BETWEEN THE TARGET LAYER AND EVALUATION GRADES

\begin{tabular}{|c|c|}
\hline Distance & $C(89.452,2.372,0.05)$ \\
\hline$C(0,20,0.05)$ & 0.3938 \\
\hline$C(65,10 / 6,0.05)$ & 0.3631 \\
\hline$C(75,10 / 6,0.05)$ & 0.3998 \\
\hline$C(85,10 / 6,0.05)$ & 0.2773 \\
\hline$C(100,10 / 3,0.05)$ & 0.5480 \\
\hline
\end{tabular}

\section{Conclusion}

Based on the study for the present literatures about the component of teacher's ability, teacher's quality and innovation talents training etc., we extracted and built the evaluation index system of mathematical teacher's ability. In view of the advantages and disadvantages of subjective weighting and objective weighting, a combination weighting method was presented to determine the weight of each indicator. For the advantages of cloud model to transform between qualitative concepts and their quantitative numerical uncertainty, the cloud model of target layer in the evaluation index system of mathematical teacher's ability is constructed by applying the theory of an improved comprehensive cloud. Furthermore, we introduced similar cloud to judge more clearly intuitive which grade the teacher's ability belongs to. The results of application studies show that evaluation method and model of the teacher's ability proposed in the paper are correct, reliable and workable.

\section{ACKNOWLEDGMENT}

The authors thank for financial support from Education Department of Sichuan Province for the project (No. 030039 007): "The system of mathematical courses about graduate students of engineering and its teaching reform and test" and the project (No.X15021301019):"The reform and practice on series of university mathematic courses in the mode of diversified talents training".

\section{REFERENCES}

[1] Jeng-Fung Chen, Ho-Nien Hsieh, Quang Hung Do. "Evaluating teaching performance based on fuzzy AHP and comprehensive evaluation approach," Applied Soft Computing. 28 (2015),pp.100-108.

[2] Zhao Yundong, Yuan Jianguo. "Research on fuzzy comprehensive evaluation of physical education teachers in colleges and universities," Journal of Beijing University of Physical Education. 2001(24)2,pp.349-251.

[3] Ren RongRong, XingGang. "A model for university teaching teacher's competence evaluation based on grey relational analysis and harmony factor,"2009 Second International Conference on Intelligent Computation Technology and Automation. 2009, 748, pp.130-133.

[4] Henna Konu. "Developing nature-based tourism products with customers by utilising the Delphi method," Tourism Management tives .Volume 14, April 2015, pp.42-54.

[5] Yao Ji, Guo H. Huang, Wei Sun. "Risk assessment of hydropower stations through an integrated fuzzy entropy-weight multiple criteria decision making method: A case study of the Xiangxi River," Expert Systems with Applications. 42 (2015) ,pp.5380-5389.

[6] Guoyin Wang, Changlin Xu, Deyi Li. "Generic normal cloud model," Information Sciences. 280 (2014),pp.1-15. 
[7] Chi Xudong. "Research on assessment index system for teachers of Beijing university of phy system," Journal of Tianjin Normal University (Natural Science Edition). 2004(24)1,pp. 66-69.

[8] Y. Tang, "Coach evaluation model based on the comprehensive weights," Advanced Materials Research, Jun. 2014,pp. 3541-3545.

[9] Lingling Li, Lixin Liu, Chunwen Yang, Zhigang Li. "The comprehensive evaluation of smart distribution grid based on cloud model," 2012 International Conference on Future Electrical Power and Energy Systems, Energy Procedia. 2012,17,pp.96 - 102.

[10] Luo Sheng, Zhang Baoming, Guo Haitao. "Image map quality comprehensive assessment based on cloud model,' Surveying and Mapping.May 2008,pp.44-46. 